\title{
A árvore da palavra banto em Minas
}

\author{
Sônia Queiroz
}

\section{SciELO Books / SciELO Livros / SciELO Libros}

QUEIROZ, S. A árvore da palavra banto em Minas. In: Palavra banto em Minas [online]. Belo Horinzonte: Editora UFMG, 2019, pp. 7-17. ISBN: 978-65-8001-003-5. https://doi.org/10.7476/9786580010035.0001.

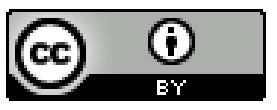

All the contents of this work, except where otherwise noted, is licensed under a Creative Commons Attribution 4.0 International license.

Todo o conteúdo deste trabalho, exceto quando houver ressalva, é publicado sob a licença Creative Commons Atribição 4.0.

Todo el contenido de esta obra, excepto donde se indique lo contrario, está bajo licencia de la licencia Creative Commons Reconocimento 4.0. 


\section{A árvore da palavra banto em Minas}

O Brasil é o país com a maior população negra fora da África e, na África, é superado apenas pela Nigéria. O primeiro Censo Demográfico da República, realizado em 1890, após a extinção do tráfico negreiro e a abolição do regime de escravidão no Brasil, apontou 53\% de negros e pardos na população brasileira. Apesar da política de branqueamento implementada pela República, mais de 200 anos depois, o Censo Demográfico Brasileiro de 2010 aponta um percentual quase idêntico: 50,7\%. 
Durante a colonização portuguesa, o regime de escravidão transportou para o território brasileiro mais de 5 milhões de africanos. Minas Gerais recebeu um dos maiores contingentes de africanos escravizados nos séculos XVIII e XIX, período em que se deu o povoamento da então capitania das Minas, impulsionado pela descoberta do ouro e das pedras preciosas na região. De acordo com Edison Carneiro, no artigo "O negro em Minas Gerais", "cerca de meio milhão de negros foi empregado na mineração do ouro e dos diamantes nos setenta anos em que essa exploração foi considerada economicamente rendosa."

A contribuição do enorme contingente de africanos trazidos para as Minas a partir do século XVIII - no plano econômico, político e cultural, aqui incluídas as artes, as línguas, as manifestações religiosas, o pensamento sobre o mundo - ainda não foi devidamente estudada. Nas décadas de 1920 a 1940, houve um interesse especial pela questão das contribuições dos africanos para a língua portuguesa e a cultura brasileira. No âmbito desse movimento, destacam-se em Minas Gerais os trabalhos de Nelson de Senna (1896-1976), que, além do livro Africanos no Brasil, publicado em 1938, deixou preparados os manuscritos de um Elucidário de africanismos, ainda inédito, disponíveis para pesquisa no Arquivo Público da Cidade de Belo Horizonte - APCBH. Em 1940, apresentou ao $9^{\circ}$ Congresso Brasileiro de Geografia um memorial, defendendo tese sobre a "Influência africana na toponímia mineira, nomes locais de acentuada origem afro-negra, ou compostos com elementos africanos". Esses dois manuscritos estão no $\mathrm{APCBH}$, à espera de editor.

Segundo Nelson de Senna, no livro Africanos no Brasil, a população afrodescendente foi maioria em Minas até o final do século XIX: em 1776, os negros e mestiços de negros somavam 249.105 indivíduos - 77,9\% da população que então totalizava 319.769 habitantes. No período entre 1786 e 1805, os escravos constituíam $47,94 \%$ e $46,38 \%$ da população, donde se pode inferir que os indivíduos de cor continuavam sendo maioria, pois, por essa época, muitos deles já eram alforriados. Em 1821, do total de 514.108 habitantes, 383.061 eram negros e mestiços de negros, o que equivale a $74,51 \%$ da população.

No início do século XXI, ainda encontramos remanescentes das culturas africanas que aqui se instalaram, constituindo núcleos de resistência cultural, muitos deles associados a atividades artísticas e religiosas, de que são talvez os exemplos mais significativos o Reinado de N. S. do Rosário e os candombes. 
No ano 2000, a Fundação Palmares (vinculada ao Ministério da Cultura), atuando junto ao Congresso Nacional e a poderes locais, "no sentido de ampliar a cultura de valorização da diversidade étnica e cultural na formulação de leis e implementação de políticas públicas", realizou o primeiro mapeamento das comunidades remanescentes de quilombos, tendo identificado 743 áreas, onde viviam cerca de 2 milhões de brasileiros. Hoje, mais de 2.600 áreas já foram certificadas pela fundação em todo o território nacional. De acordo com o Quadro Geral de Comunidades Remanescentes de Quilombos (CRQ's), em Minas Gerais, até maio de 2017, a pesquisa da Fundação Palmares identificou 294 comunidades remanescentes de quilombos. Por outro lado, o levantamento feito em Minas pelo CEDEFES - Centro de Documentação Eloy Ferreira da Silva, na pesquisa Comunidades quilombolas em Minas Gerais no século XXI, realizada por Maria Elisabete Gontijo dos Santos e Pablo Matos Camargo, em 2007 já tinha identificado 439 comunidades quilombolas.

Não há dúvida, portanto, sobre a forte contribuição dos africanos e seus descendentes na construção da nossa cultura.

Considerando-se a escassez de informação referente aos africanos trazidos para o Brasil como escravos - já que foi queimada a documentação oficial relativa ao tráfico, em obediência à circular de 13 de maio de 1892, do Ministério da Fazenda - e a quase inexistência de documentos linguísticos do período da escravidão, os estudos dos casos de resistência cultural revestem-se de grande importância, na medida em que constituem uma fonte essencial para a determinação dos grupos de africanos que se concentraram nas diversas regiões do País, seus remanescentes culturais, tais como os cultos religiosos, o artesanato, a música, a dança, a língua e a literatura oral.

Nos últimos anos parece ter se renovado o interesse pelos estudos sobre o negro no Brasil. É preciso ressaltar o papel essencial dos movimentos sociais, como o Movimento Negro Unificado, dentre outros, e da nova Constituição Brasileira, que afirma o direito à diferença: escola diferenciada, respeito aos cultos religiosos e manifestações culturais afro-brasileiras. Mais recentemente, a Lei $n^{\circ} 10.639$, sancionada pelo Presidente da República em 9 de janeiro de 2003 e revisada na Lei 11.645/2008, tornou “obrigatório o ensino sobre História e Cultura Afro-Brasileira", e veio reforçar oficialmente, pela via do sistema educacional, o reconhecimento das culturas africanas como elemento integrante da cultura brasileira e justificar o investimento na pesquisa e na produção de material que sirva à difusão 
do conhecimento da história e das manifestações linguísticas e artísticas dos povos africanos que participam da história e da composição étnica do Brasil.

Passados três séculos da chegada às Minas dos primeiros africanos e seus descendentes nascidos na América, trazidos para o trabalho forçado nas minas de ouro e pedras preciosas no século XVIII, as línguas africanas mais faladas aqui - o quimbundo, o quicongo e o umbundo - se restringem hoje a fragmentos: linguagem ritual em algumas comunidades quilombolas, versos e palavras soltos em alguns cantos do repertório das festas de N. S. do Rosário e do candombe (que se realiza também fora do âmbito da festa do Rosário).

Em terreiros de candomblé, na Bahia, Yeda Pessoa de Castro constatou o que ela designou competência simbólica: o povo de santo que canta em iorubá conhece o sentido do canto, sua inserção ritual, mas não conversa em iorubá. Trata-se de uma língua ritual, de uso restrito, que não se utiliza para fins de comunicação cotidiana. Entendo que esse conceito pode aplicar-se bem às ocorrências de palavras africanas em contos narrados em língua portuguesa, ainda que, no caso dos contos, os narradores comumente conheçam explicitamente o significado das palavras africanas. A palavra, aqui, para além de signo, norteia um sentido simbólico, ou mesmo icônico.

O diálogo entre canto e conto é constante na tradição banto e também no Brasil, como uma possível forma de herança. No decorrer da narrativa dos contos, ocorre muitas vezes a inserção de um canto na voz de personagens. Nesta situação, diferentemente da competência linguística, as palavras não são utilizadas em outro contexto que não seja o dos versos, como observa Yeda Pessoa de Castro também em relação aos cantos iorubá. Os cantadores, e também contadores, desconhecem o significado de cada palavra isoladamente, mas sabem a função daquele canto, a que ou a quem se destina, enfim, seu fundamento (termo usado pelos próprios cantadores para designar o sentido simbólico do canto).

No que diz respeito ao contato das línguas africanas com o português, essas línguas foram se integrando gradativamente, formando o português brasileiro. O conceito de falares de emergência, proposto por Yeda Pessoa de Castro, no artigo "Influências de línguas africanas no português do Brasil e níveis sócio-culturais de linguagem", publicado em 1977, aponta para esse comportamento histórico das línguas africanas no Brasil. A etnolinguista baiana formula a ideia de um continuum linguístico, identificando nesse continuum três fases: primeiro, o dialeto das senzalas, quando houve a mistura de diferentes línguas africanas, com predomínio das línguas do 
grupo banto, no primeiro momento da colonização brasileira, com a utilização de africanos escravizados como mão de obra nos engenhos de cana de açúcar. Num segundo momento, teria havido a intensificação do contato entre negros e brancos, especialmente no período mineratório, quando a economia se desloca do Nordeste para o Sudeste, com a descoberta das minas de ouro e diamante. Ocorre, então, um outro tipo de povoamento, com a constituição das vilas, e os africanos e seus descendentes são utilizados também no trabalho doméstico, servindo na casa, e assim intensificando o contato com a língua portuguesa. Com isso, o dialeto das senzalas, resultante da mistura de várias línguas africanas, começa a misturar-se à língua portuguesa. Yeda Pessoa de Castro chama de dialeto das minas o falar resultante desse segundo momento de contato linguístico. Em seguida, teria havido novas misturas, nas vilas de mineração e nas fazendas do gado, no ciclo do couro, resultando no dialeto rural. Esta hipótese parece bastante consistente, afinal, de acordo com os levantamentos feitos ao longo da nossa pesquisa, os falares, cantos e contos em que se verifica a presença da palavra banto situam-se justamente no ambiente do dialeto rural.

\section{A árvore da palavra}

Das 439 comunidades negras de Minas Gerais levantadas pelo CEDEFES, pudemos identificar, até o momento, 11 em que há registro impresso, sonoro ou em vídeo de remanescentes de línguas africanas do grupo banto: Tabatinga (Bom Despacho), Calunga (Patrocínio), Catumba (Itaúna), Jatobá (Belo Horizonte), Arturos (Contagem), Matição ou Mato do Tição (Jaboticatubas), Milho Verde (Serro), Quartel do Indaiá e São João da Chapada (Diamantina), Fagundes (Santo Antônio do Amparo) e Oliveira.

Desde 1981, realizamos diversas pesquisas em torno dos falares, contos e cantos de algumas dessas comunidades, que, posteriormente, seriam de grande importância para a realização do projeto $A$ árvore da palavra: falares, contos e cantos da tradição banto no Brasil, que deu origem ao glossário que agora apresentamos. O livro publicado em 1998, pela Editora UFMG, sob o título Pé preto no barro branco: a língua dos negros da Tabatinga, abordou, como o próprio título evidencia, a língua falada na comunidade da Tabatinga, em Bom Despacho. Em outro estudo, desenvolvido a partir de 2002, focamos os vissungos, que são cantos herdados dos negros africanos, de que ainda pudemos ouvir fragmentos nas comunidades do Baú, Ausente e Milho 
Verde, no município do Serro, e Quartel do Indaiá e São João da Chapada, no município de Diamantina. Esses cantos, que, de acordo com o encarte do CD Congado mineiro, ora expressam "a dor e o cansaço dos carregadores caminhando léguas a pé entre as serras", ora "marcam o momento em que, aproximando-se do cemitério, os companheiros encomendam a alma do morto, para que possa ganhar com suavidade a terra dos ancestrais", hoje só são cantados em ocasiões muito especiais, como no enterro de Antônio Crispim Veríssimo, mestre de vissungo, integrante do catopê de Milho Verde, falecido em 2008.

Os vissungos são um tipo de canto responsorial, em que o mestre puxa o canto e o grupo responde. Geralmente o coro responde repetindo, sem acréscimo, alguns dos versos cantados pelo solista, não havendo disputa de quem é melhor - o que o diferencia do desafio do Nordeste, que é uma disputa entre mestres do canto: um cantador joga versos para o outro, que tem que dar conta de responder à altura. Os vissungos são cantos para várias ocasiões: há o canto para saudar o dia, o amanhecer, o nascer do sol; o canto do meio-dia, que é a hora da alimentação; o canto de multa, que é para abordar um forasteiro que chegou ao trabalho de mineração; o canto do término do trabalho; e o já mencionado canto de enterro, que recentemente foi objeto do documentário dirigido por Rodrigo Siqueira, intitulado Terra deu, terra come, premiado no Rio de Janeiro, no festival É tudo verdade em 2010. Ainda sobre os vissungos, acompanhamos o trabalho de campo da pesquisadora Lúcia Valéria do Nascimento (realizado no âmbito de seu mestrado, em 2003, no Programa de Pós-Graduação em Estudos Linguísticos da Faculdade de Letras da Universidade Federal de Minas Gerais (FALE/UFMG), intitulado A África no Serro-frio - Vissungos: uma prática social em extinção), e tivemos a oportunidade de conhecer as comunidades do Baú e Ausente, e verificar a permanência de alguns elementos culturais de tradição banto.

Realizamos o levantamento dos registros de falares africanos em Minas Gerais, no âmbito do projeto A árvore da palavra, desenvolvido entre 2011 e 2014. Destacam-se a pesquisa de João Dornas Filho - realizada no povoado de Catumba, no município de Itaúna, Oeste de Minas, e publicada inicialmente na Revista do Arquivo Municipal, de São Paulo, em 1938 - e o trabalho importantíssimo desenvolvido na região de Diamantina por Aires da Mata Machado Filho, que registrou 65 cantos, com "letra, música e tradução, ou antes 'fundamento'", dois glossários da "língua banguela" (um extraído dos cantos e o outro, do falar local), além de oito capítulos de estudo sobre a cultura afrobrasileira no contexto da mineração de diamantes. Este trabalho, 
publicado inicialmente em capítulos, na mesma Revista do Arquivo Municipal, de São Paulo, entre 1939 e 1940, foi editado e reeditado em livro - José Olympio (1943), Civilização Brasileira (1964) e Itatiaia (a partir de 1985) - e permitiu diversas gravações sonoras, a partir de 1944, e fílmicas, a partir de 1985.

Na década de 1940, Luiz Heitor Corrêa de Azevedo, contemporâneo e companheiro de Mário de Andrade na pesquisa etnográfica, com financiamento da Biblioteca do Congresso Americano, foi pioneiro no registro sonoro dos cantos de trabalho e de enterro no município de Diamantina (a mesma região em que pesquisou Aires da Mata Machado Filho), entoados em "dialeto banguela", como denominavam ali o falar resultante do contato de africanos de línguas do grupo banto trazidos para as Minas, provavelmente a partir do porto de Benguela, em Angola. Parte desse acervo (quatro vissungos) foi digitalizada e disponibilizada em 1997, no CD L. H. Corrêa de Azevedo: music of Ceara and Minas Gerais. Em 1985, foi gravado o LP O canto dos escravos, por Clementina de Jesus, Doca e Geraldo Filme, ao qual se seguem, mais tarde, diversas outras gravações em CD. Atualmente, com os avanços tecnológicos, o registro digital vem sendo realizado no Sudeste brasileiro com muita qualidade por associações culturais como Cachuera! e Viola Correa, com o patrocínio do Itaú e da Petrobras Cultural. Destacam-se também iniciativas isoladas de artistas-pesquisadores, como Titane e Caxi Rajão. À iniciativa e qualidade do trabalho dos músicos e etnomusicólogos, e de toda a equipe desses pesquisadores da música de tradição oral no Brasil, deve-se o registro sonoro (e, em alguns casos, também escrito e em DVD) dos cantos utilizados nesta pesquisa.

Os exemplos mencionados acima ilustram os raros registros dos falares, contos e cantos de tradição oral banto em Minas. O estudo desses cantos numa abordagem comparativa, levando em consideração as relações entre as línguas e outras manifestações culturais africanas, demanda dedicação e tempo sobre os textos de cá e de lá do Atlântico. O primeiro passo para esse estudo, no entanto, é a reunião dos falares, dos cantos - música e letra - e dos contos, em suporte material, o que exige deslocamento e equipamento para gravação e transcrição. Por isso, reiteramos, as recolhas e gravações já feitas são de grande valor para o desenvolvimento da pesquisa.

No estágio de pós-doutoramento realizado entre 2007 e 2008 na UNEB-Salvador, com a supervisão da etnolinguista Dra. Yeda Pessoa de Castro, pudemos reunir um repertório de mais de 100 contos da tradição oral dos povos de línguas do grupo banto - especialmente quicongo, 
quimbundo e umbundo - publicados em língua portuguesa a partir de recolhas feitas em Angola e em Moçambique; e de outros quase 100 contos recolhidos na tradição oral de Minas Gerais. O projeto, intitulado Minas afrodescendente: histórias da tradição banto, tinha como objetivo identificar histórias trazidas pelos falantes das línguas banto ao Brasil, contribuindo, assim, para a identificação de uma poética banto na tradição oral de Minas. Identificamos nesses contos relações transtextuais, ou hipertextuais, que chamamos de ressonâncias, com base em conceito cunhado por Mikhail Bakhtin para designar o efeito provocado pela multiplicidade de sentidos no encontro de enunciados no fluxo da rede de comunicação verbal. Segundo Bakhtin, um discurso só se constrói pelo atravessamento de uma variedade de outros discursos, quando as palavras já são habitadas por ressonâncias. A esse encontro, Bakhtin deu o nome de ressonância dialógica.

Durante a leitura das coletâneas de contos recolhidos de um e de outro lado do Atlântico, encontramos em recolhas mineiras alguns contos que não apresentaram ressonância com os contos africanos no enredo, mas que contêm no texto palavras de línguas do grupo banto. Trata-se, portanto, de um outro tipo de relação, não mais entre os textos, mas, sim, entre as línguas de transmissão dos textos, ou, ainda, entre texto e palavra (no sentido de 'vocábulo' e também no sentido de 'discurso', 'parábola').

Decidimos, então, continuar investigando, a partir das palavras de línguas africanas do grupo banto presentes em falares, contos e cantos registrados no Brasil, o trânsito etnopoético dos textos. Atentando ao campo semântico e simbólico dessas palavras, ao seu nível de integração no português brasileiro, o objetivo era refletir sobre o contato etnolinguístico e a preservação de línguas africanas no Brasil, a memória e a competência simbólica banto evidenciadas em narrativas orais e cantos. Que histórias nos contam as palavras africanas escolhidas para guardar a memória dos bacongo, dos ambundo e dos ovimbundo em terras brasileiras? Poderíamos identificar esse fenômeno de ressonância linguística e hipertextual nas narrativas orais e nos cantos com recursos etnopoéticos recorrentes na literatura africana escrita publicada nos últimos anos? Pensar essas ressonâncias de caráter linguístico e cultural nos ajuda a entender o quão próximos somos da África.

A rede de cerca de 129 narrativas levantadas nessa busca foi digitalizada e editada em CD-ROM, de modo a facilitar outros trabalhos. A pesquisa produziu ainda livros-objetos, transcriações a partir da leitura comparada dos contos ressonantes. Os livros-objetos foram expostos em 2008, em Belo 
Horizonte, na Faculdade de Educação da UFMG, dentro da programação do Jogo do Livro, e na Serra do Cipó, no seminário Da Cópia ao Canto, organizado pelo núcleo de pesquisa Literaterras, da Faculdade de Letras da mesma universidade.

A frente de pesquisa do vocabulário banto em todo o território de Minas teve início em 2005, com o projeto de iniciação científica da estudante Amanda Sônia Lopez de Oliveira, a partir de dados colhidos por mim na pesquisa de campo e na pesquisa bibliográfica realizadas em torno da língua da Tabatinga. Com a minha orientação, Amanda compilou os vocabulários de origem africana resultantes de recolhas realizadas em Minas Gerais, em comunidades negras caracterizadas como núcleos de resistência cultural (comunidades quilombolas). A compilação foi publicada inicialmente em 2006 pelas Edições Viva Voz, da Faculdade de Letras da UFMG, com o título Palavra africana em Minas Gerais.

Realizamos em seguida trabalho de identificação dos prováveis étimos umbundo, quimbundo e quicongo dos vocábulos constantes dessa compilação, bem como a ampliação do vocabulário, com a incorporação dos vocábulos de provável origem africana presentes nos contos orais, nos cantos do Reinado de N. S. do Rosário, e na toponímia mineira - estes levantados por Emanoela Cristina Lima, que desenvolveu em seu mestrado na Faculdade de Letras da UFMG pesquisa sobre a toponímia de origem africana no território de Minas Gerais, intitulada A toponímia africana em Minas Gerais. Para a ampliação do acervo de contos em muito contribuiu a pesquisa de doutoramento Do canto da voz ao batuque da letra: a presença africana em narrativas orais inscritas no Brasil, de Josiley Souza, que identificou as ressonâncias entre contos da tradição oral de Angola, Moçambique e Brasil, ampliando e aprofundando a pesquisa anterior, já mencionada, desenvolvida por nós no âmbito de Minas Gerais.

Destaca-se também a pesquisa de doutorado Vissungo: o cantar banto nas Américas, realizada na Faculdade de Educação da UFMG por Andrea Adour, com a minha coorientação, que buscou, através de estudo dos primeiros registros escritos e fonográficos das músicas de raiz africana nas Américas, distinguir os elementos musicais relacionados à presença das culturas banto no Brasil e nos Estados Unidos.

Como parte dos resultados de nossas pesquisas, três títulos foram publicados pelas Edições Viva Voz: a coletânea Vissungos: cantos afrodescendentes em Minas Gerais, organizada por mim e Neide Freitas Sampaio, lançada em 2015, e já em terceira edição revista e ampliada, reúne estudos sobre os cantos 
de tradição banto remanescentes em Minas no século XX e XXI; o audiolivro Vissungos no Rosário: cantos da tradição banto em Minas, organizado por mim, lançado em 2016, e também já em terceira edição revista e ampliada, reúne cantos que ainda guardam traços das línguas e culturas dos africanos trazidos para o trabalho forçado nas minas de ouro e pedras preciosas no século XVIII e, ao final, apresenta um glossário; e o audiolivroVissungos e a MPB: a palavra africana em canções de compositores mineiros, organizado por Andrea Adour, lançado em 2017, registra a presença de palavras africanas no contexto da música popular brasileira.

A elaboração deste glossário passou por três momentos. No primeiro momento, foi realizada a compilação dos vocabulários afrobrasileiros recolhidos em Minas por diferentes pesquisadores. Em seguida à primeira formulação dos verbetes, buscamos os registros das palavras na lexicografia brasileira: registros de "africanismos" em dicionários e glossários do português falado no Brasil. Num terceiro momento, buscamos em dicionários de línguas africanas do grupo banto - prioritariamente as três já identificadas como predominantes no Brasil: quimbundo, quicongo e umbundo os prováveis étimos dos vocábulos constantes da compilação. Finalmente, buscamos ocorrências dos vocábulos que integram este glossário na literatura angolana escrita a partir da segunda metade do século $\mathrm{XX}$, pelos seguintes autores: Óscar Ribas, Uanhenga Xitu, Luandino Vieira, Pepetela, Manuel Rui e Ondjaki. A partir da terceira etapa do trabalho, contamos com a colaboração de Neide Freitas Sampaio, que atuou na pesquisa de étimos e de ocorrências em obras da literatura angolana que contemplam o contato entre a língua portuguesa e línguas do grupo banto e que, em sua pesquisa de mestrado, orientada por mim, intitulada Por uma poética da voz africana: transculturações em romances e contos africanos e afro-brasileiros, buscou ocorrências dos vocábulos em toda a obra literária de Luandino Vieira.

Nossa compilação resultou em um total de 761 vocábulos de origem banto. A maior parte foi identificada em falares, seguida pelos nomes de lugares e, em menor número, as palavras de origem banto permanecem nos contos orais e nos cantares, que estiveram no dia a dia dos negros e hoje se restringem aos contextos rituais. Dos 12 campos lexicais identificados, predominam palavras relacionadas à natureza, seguidas por pessoas e relações, alimentação e corpo, como já havíamos verificado em nossa primeira pesquisa, com a língua da Tabatinga. Em menor número, encontram-se palavras relacionadas a utensílios, festas, profissões e religiosidade. Uma minoria se refere a fala e escrita, doença e morte, e vestuário. 
Com a elaboração deste glossário buscamos realizar uma arqueologia do contato entre línguas africanas do grupo banto e a língua portuguesa no Brasil. Apresentamos agora na forma de livro o resultado da garimpagem: Palavra banto em Minas.

Sônia Queiroz 



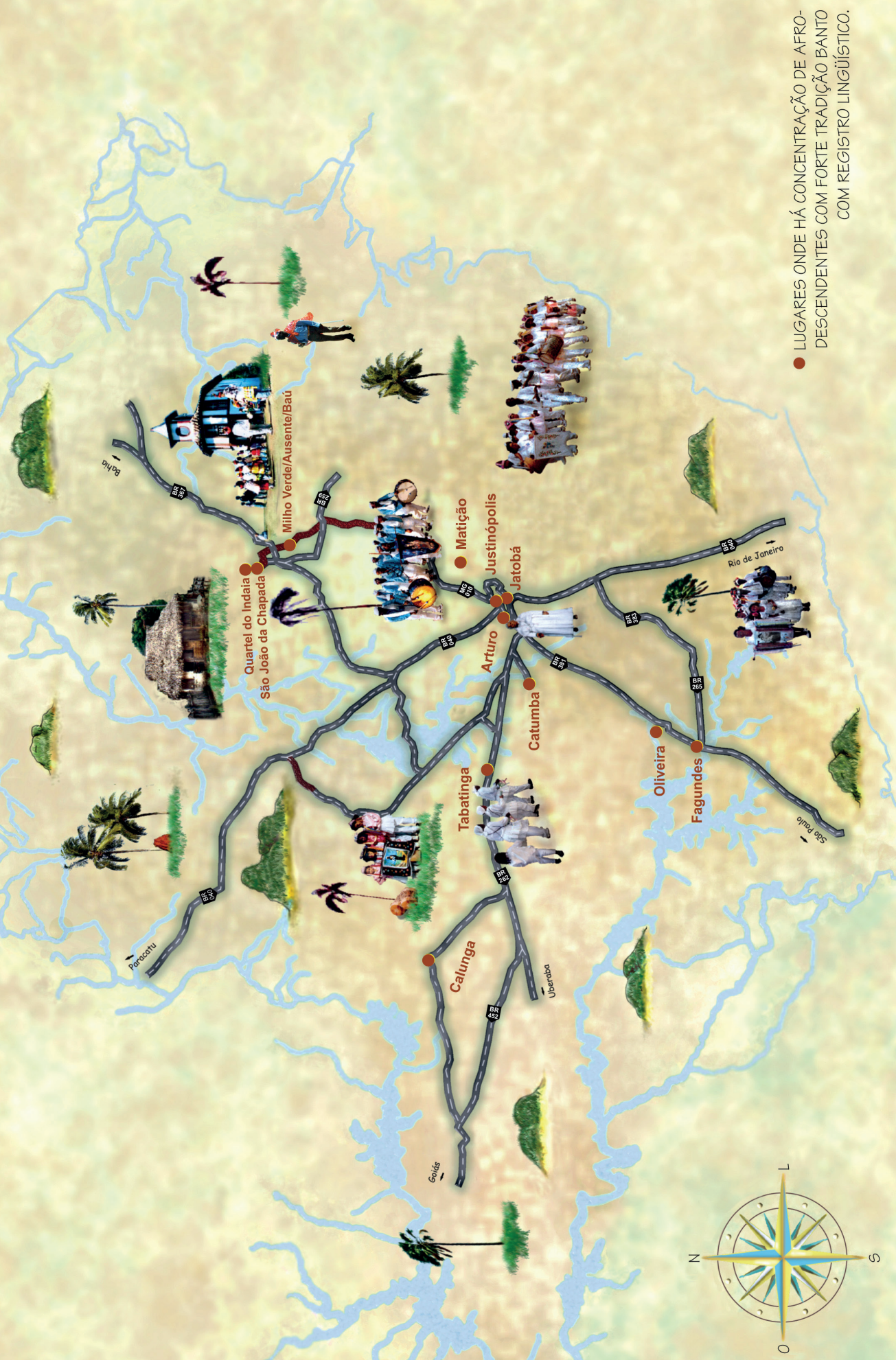

